\title{
First Record of Pseudomonas syringae pv. syringae in Iraq using Conventional and Specific PCR Protocol
}

\author{
${ }^{1}$ Wazeer A. Hassan, ${ }^{2}$ Farida F. Nerweyi, ${ }^{3}$ Jivan M. M. Al-Doski \\ 1, 3: Univ. of Duhok, Faculty of Agric. \& Forestry, Plant Protection Dept. \\ 2: Univ. of Duhok, Faculty of Science, Biology Dept.
}

\begin{abstract}
Bacterial canker and gummosis of stone fruits caused by Pseudomonas syringae pv. syringae Van Hall (Pss ) were mostly found on dormant buds, blossoms, twigs and trunks rather than leaves and fruits in Duhok, Northern of Iraq. In this work, 262 symptomatic diseased samples collected from apricot, plum and peach trees (dormant buds, flowers, twigs and trunks) during early spring and late summer 2012. The conventional and Polymerase Chain Reaction (PCR) techniques managed to detect and characterize Pss . PCR protocol described uses specific primers $C$-Duhok B1 and B2 to identification main virulence factor Syringomycin (syrB) gene for the detection of Pss. Diseased samples were initially screened on $5 \%$ Nutrient Agar Sucrose (NAS) and 5\% Nutrient Broth Sucrose (NBS), selective media of Pseudomonas Agar Base (PAB). Therefore, 139 samples were considered $P$. syringae. Subsequently, confirmations of 62 isolates from 139 were considered to be of P. syringae on Cetrimide Agar (CA). These isolates found to be gram negative bacilli, short rods and non spore-form and characterized by negative oxidase and leaven positive on 5\% NAS. PCR was carried out for 62 P. syringae isolates for detection of Pss, using syrB primer with size 752 bp. Results showed that 13 of $62(21 \%)$ isolates carried syrB gene and similarly in the biochemical characters using Analytical Profile Index (API 20NE). Thus, characterization of Pss strains to hydrolysis Esculin, Gelatin and fruit contents of Glucose, Arabinose, Mannose, Mannitol, Capric and Malic acid. Other biochemical analysis was also documented. PCR identification of Pss considers the first certified record for these suspected and serious phytopathogenic bacteria in Iraq.
\end{abstract}

Key Word: Canker, Bacterial Disease, Stone Fruit Trees, Pseudomonas syringae Pv. syringae.

\section{Introduction}

Bacterial canker is the most devastating disease in apricot, peach, plum and cultivated cherry as well as wild cherry. It become a serious problem in many parts of the world that results from limited tree orchard life duration and direct reduction in yield between $10-20 \%$ in young orchards and even up to $80 \%$ under favorable climatic conditions (Cameron, 1962; Ogawa and English, 1991; Young, 1991; Mohammadi et al., 2001). Bacterial canker of stone fruits is caused by two closely related pathovar, Pseudomonas syringae pv. syringae (Van Hall) and pv. morsprunorum (Wormald), they belong to genomospecies 1 and 2, respectively and are an important disease of apricot and other stone fruits (Young, 1991; Gardan et al., 1999; Roberts and Smith, 2002; Kennelly et al., 2007). The Identification of $P$. syringae and pathovars immediately after 1980 , the detection of plant pathogenic species could still be based on simple phenotypic tests (Young, 2010). However, the use of determinative tests with primary reliance was shown to be of limited value for classification and differentiation of $P$. syringae pathovars (Young and Triggs, 1994; Palleroni, 2005). Increasingly orientated towards poly-phasic and molecular methods for identify, differentiate and classify closed bacteria at the sub species level (Najafi and Taghavi, 2014). As mentioned by Palacio-Bielsa et al. (2009) PCR primers can offer a reliable method for the confirmation of identity pathovars.

This work aimed to identification of the isolated pathogenic bacterial pathovars at first time in Iraq using traditional then confirmed by PCR techniques.

\subsection{Samples Collection:}

\section{Material and Methods}

Diseased samples of apricot, plum and peach trees (dormant buds, flowers, twigs and trunks) with typical bacterial canker and shot-hole symptoms were collected from six localities of Duhok province (Green Valley, Shendokha, Bagera, Akre, Dlebe and Fedeye) (Table 1), during early spring and late summer of 2012. A total number of 262 symptomatic diseased samples were assembled, including 104 samples originated from peach, 104 from apricot and 54 from plum tissues. 
First Record of Pseudomonas syringae pv. syringae in Iraq using Conventional and Specific PCR

Table 1: Location, host, plant parts and designation of bacterial isolates during 2012 from different situations in Duhok governorate

\begin{tabular}{|c|c|c|c|c|c|c|c|}
\hline Location & Host & $\begin{array}{c}\text { Plant } \\
\text { part }\end{array}$ & *Designation of isolates & Location & Host & $\begin{array}{c}\text { Plant } \\
\text { part }\end{array}$ & *Designation of isolates \\
\hline \multirow{5}{*}{ Akre } & \multirow{2}{*}{ Peach } & Twigs & AkPeTw & \multirow{10}{*}{ 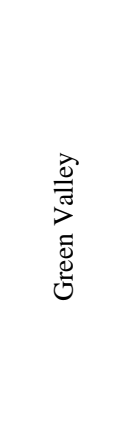 } & \multirow{4}{*}{ Peach } & Flowers & GvPeFl \\
\hline & & Trunks & AkPeTr & & & Buds & $\mathrm{GvPeBu}$ \\
\hline & \multirow{2}{*}{ Apricot } & Twigs & AkApTw & & & Twigs & GvPeTw \\
\hline & & Trunks & AkApTr & & & Trunks & GvPeTr \\
\hline & Plum & Trunks & AkPlTr & & \multirow{3}{*}{ Apricot } & Buds & GvApBu \\
\hline \multirow{9}{*}{ Shendokha } & \multirow{4}{*}{ Peach } & Flowers & ShPeFl & & & Twigs & GvApTw \\
\hline & & Buds & $\mathrm{ShPeBu}$ & & & Trunks & GvApTr \\
\hline & & Twigs & ShPeTw & & \multirow{3}{*}{ Plum } & Flowers & GvPlFl \\
\hline & & Trunks & ShPeTr & & & Buds & GvPIBu \\
\hline & Apricot & Flowers & ShApFl & & & Twigs & GvPlTr \\
\hline & \multirow{4}{*}{ Plum } & Flowers & ShPIFl & \multirow{6}{*}{ Dlebe } & \multirow{2}{*}{ Peach } & Twigs & DlPeTw \\
\hline & & Buds & ShPlBu & & & Trunks & DlPeTr \\
\hline & & Twigs & ShPITw & & \multirow{4}{*}{ Apricot } & Flowers & DlApFl \\
\hline & & Trunks & ShPITr & & & Buds & DlApBu \\
\hline \multirow{6}{*}{ Bagera } & \multirow{4}{*}{ Peach } & Flowers & $\mathrm{BaPeFl}$ & & & Twigs & DlApTw \\
\hline & & Buds & $\mathrm{BaPeBu}$ & & & Trunks & DlApTr \\
\hline & & Twigs & BaPeTw & \multirow{4}{*}{ Fedeye } & \multirow{4}{*}{ Peach } & Flowers & $\mathrm{FePeFl}$ \\
\hline & & Trunks & $\mathrm{BaPeTr}$ & & & Buds & $\mathrm{FePeBu}$ \\
\hline & \multirow{2}{*}{ Apricot } & Flowers & $\mathrm{BaApFl}$ & & & Twigs & FePeTw \\
\hline & & Buds & $\mathrm{BaApBu}$ & & & Trunks & $\mathrm{FePeTr}$ \\
\hline
\end{tabular}

*Isolates design constitute the abbreviation of the first two letters for each location, host and plant part, respectively.

\subsection{Isolation of Pseudomonas syringae pv. syringae :}

Pseudomonas species in general have simple nutritional requirements and were readily isolated from disease tissues. Pss isolation was carried out by modified method of Fahy and Persley (1983) in the Research Laboratory in Plant Protection Department, Faculty of Agriculture and Forestry using 5\% Nutrient Agar Sucrose (NAS), 5\% Nutrient Broth Sucrose (NBS) and Pseudomonas Agar Base (PAB).

\subsubsection{Identification of Pseudomonas syringae pv. syringae using traditional methods:}

After the incubation period, light cream to yellow and mucoid sheen colonies of suspected Pss appeared on NAS and PAB plates, respectively with yellowish white supernatant fluid on NBS. The suspected colonies on both media agar plates were confirmed by streaking on Cetrimide Agar (CA) and identified morphologically as Pss .

Microscopic Study: The morphological study was performed by Gram's staining method. It was used to determine the size, shape, arrangement and gram reaction of isolates.

Oxidase Test: Looking for cytochrome enzymes a filter paper was saturated with $1 \%$ Kovac's oxidase reagent (tetra-methyl-p-phenylenediamine dihydrochloride) and placed in a clean Petri dish. A suspected colony of Pss from CA was transferred with wooden stick to the filter paper and rubbed onto the reagent for 5-10 second (York et al., 2004).

Biochemical Tests (API 20NE): API 20NE is a standardized, easy and quick system for the identification of non-fastidious, non-enteric gram-negative rods (e.g. Pseudomonas, Acinetobacter, Flavobacterium, Moraxella, Vibrio, Aeromonas, etc.), combining 8 conventional and 12 assimilation tests. Further, the identification of bacterial strains using API 20NE gave a basic confirmation for the Family Pseudomonadaceae aimed to approve the identification of the genus and species level of the epiphytic strains. 
A. Preparation of the API 20NE Strip: The $5 \mathrm{ml}$ of distilled water was distributed into the tray bottom to create a humid atmosphere with recording the specimen number on the elongated flap of the tray, the strip was kept in the incubation box.

B. Preparation of the Pss Inoculum: Suspected isolates were grown on 5\% NAS medium and followed by picked up 4 colonies from young cultures (18-24hrs old) with identical morphology from the agar plate and suspended in $2 \mathrm{ml}$ of normal saline.

C. Inoculation of the Strip: The bacterial saline suspension was distributed into the cupules of the following tests: $\mathrm{NO}_{3}$, TRP, GLU, ADH, URE, ESC, GEL and PNPG using pipette and then approximately $200 \mu \mathrm{l}$ was added of the remaining saline suspension to the ampule of API AUX Medium. Fill the cupules of the following tests: GLU, ARA, MNE, MAN, NAG, MAL, GNT, CAP, ADI, MLTM, CIT and PAC with the suspension to defect a flat or slightly convex. Then, mineral oil was added to the cupules of the tests $\underline{\text { GLU}}, \underline{\mathrm{ADH}}$ and $\underline{\mathrm{URE}}$ until a convex meniscus was formed. Finally, the incubation boxes were closed and incubated at $28 \pm 2{ }^{\circ} \mathrm{C}$ for 24 and $48 \mathrm{hrs}$ before reading the results.

\subsubsection{PCR identification of Pseudomonas syringae pv. syringae}

Yellow light cream colonies on CA were sub-cultured on 5\% NBS and then genomic DNA was extracted by Mini Kit methods. DNA was amplified by Polymerase Chain Reaction (PCR) using specific primers CDuhok B1 and B2 of 21-mer oligonucleotides from syrB gene for the detection of $P$. syringae pv. syringae. The primers B1 and B2 locate into the open reading frame of the syrB gene and yield a 752-bp product (Sorensen et al., 1998).

Genomic DNA Extraction: Genomic DNA preparation of Pss isolates strains were carried out by Genomic DNA Mini Kit which provides an efficient method for purifying DNA (Vogelstein and Gillespie, 1979).

DNA Concentration Measuring: DNA concentration was measured by using Nanodrop instrument, where $1 \mu 1$ of isolated DNA was taken and put on Nanodrop instrument and measured electronically by computer with adsorption reading at 260/280 nanometer (Tyc, 2011). DNA purity was measured according to the following equation. In this research we obtained pure DNA which was about (1.46- 2.56).

$$
\text { DNA Purity }=\frac{\text { Adsorption reading at } 260}{\text { Adsorption reading at } 280}
$$

Electrophoresis: Agarose Gel Electrophoresis, Loading Buffer and Gel Running were done according to Maniatis et al., 1982.

Ethidium Bromide Staining: The gel was removed carefully and put in Ethidium bromide staining solution and left for $1-1.5 \mathrm{hrs}$, the gel was viewed under UV light and findings were documented by photography (Gaafar et al., 2006; Pour and Taghavi, 2011).

Specific PCR Protocol: PCR employed with specific primers for syringomycin (syrB) gene in the amplification reaction for detection of syringomycin toxin gen (Takemoto, 1992). The syrB1 and syrB2 primers and components were mixed in the same amplification reaction (Table 2). Appropriate thermocycling program was set on thermocycler for syringomycin toxin (syrB1, syrB2) gene as Pre-PCR $94 \mathbf{C}^{\mathbf{0}}$ for 5 min; Thermocycling (35 cycles): Denaturation $94 \mathrm{C}^{0}$ for $1.5 \mathrm{~min}$, Annealing $60 \mathrm{C}^{\circ}$ for $1.5 \mathrm{~min}$, Extension $72 \mathrm{C}^{\mathrm{o}}$ for $3 \mathrm{~min}$ and Final Extension $\mathbf{7 2} \mathbf{C}^{\mathbf{0}}$ for $\mathbf{1 0} \mathbf{~ m i n}$.

Table 2: The component required for specific primers syrB1 and syrB2 amplification.

\begin{tabular}{|l|l|l|}
\hline Components & Volume of one reaction & $\mathbf{n} \times$ Reaction \\
\hline Deionise distil water & $15.8 \mu 1$ & $\mathrm{n} \times 15.8 \mu 1$ \\
\hline $10 \mathrm{x}$ buffer with $\mathrm{Mgcl}_{2}$ & $2.5 \mu 1$ & $\mathrm{n} \times 2.5 \mu 1$ \\
\hline dNTP mixture & $2.5 \mu 1$ & $\mathrm{n} \times 2.5 \mu 1$ \\
\hline Reverse primer & $1 \mu 1$ & $\mathrm{n} \times 1 \mu 1$ \\
\hline Forward primer & $1 \mu 1$ & $\mathrm{n} \times 1 \mu 1$ \\
\hline Taq polymerase & $0.2 \mu 1$ & $\mathrm{n} \times 0.2 \mu 1$ \\
\hline Made a master mix and then sub-divided as $23 \mu 1$ aliquots to $\mathrm{n}$ eppendorf tubes \\
\hline Sample DNA & $2 \mu 1$ to each respective tube \\
\hline Total & $25 \mu 1$ final reaction volume each \\
\hline
\end{tabular}




\section{Results and Discussion}

\subsection{Isolation of Pseudomonas syringae pv. syringae}

The successful isolation of $P$. syringae pv. syringae ( $P s s)$ was performed immediately after the appearance of the initial symptoms in early spring. 5\% Nutrient Agar Sucrose (NAS), 5\% Nutrient Broth Sucrose (NBS), Pseudomonas Agar Base (PAB) and Cetrimide agar (CA) were used as plating media. Symptomatic of 262 diseased samples were initially screened on NAS and NBS. Growth of bacterial colonies after $72 \mathrm{hrs}$ under aerobic conditions at $28 \pm 2^{\circ} \mathrm{C}$ resulted in 262 round $2-3 \mathrm{~mm}$ in diameter, light cream with entire margins, dome shaped, shiny, smooth and mucoid on 5\% NAS. A yellow supernatant fluid was showed when grown on 5\% NBS media. The same descriptions were observed by Mohammadi et al., (2001) and Karimi-Kurdistani and Harighi, (2008). PAB was used as selective media for Pss and resulted in 139 outcomes from 262 of the suspected bacterial isolates on NAS and NBS identified as Pseudomonas syringae, characterized with round colonies 1-3 $\mathrm{mm}$ in diameter, yellow with complete margins, conk shaped, sparkly, smooth, and fluorescent after 2-4 days at $28 \pm 2^{\circ} \mathrm{C}$. Selective media CA was used for confirmation and avoiding of full inhibition of the contamination as recommended by Moore et al., (2006) (Figure 1). Finally, 62 isolates were identified and considered to be Pseudomonas syringae (Table 3).

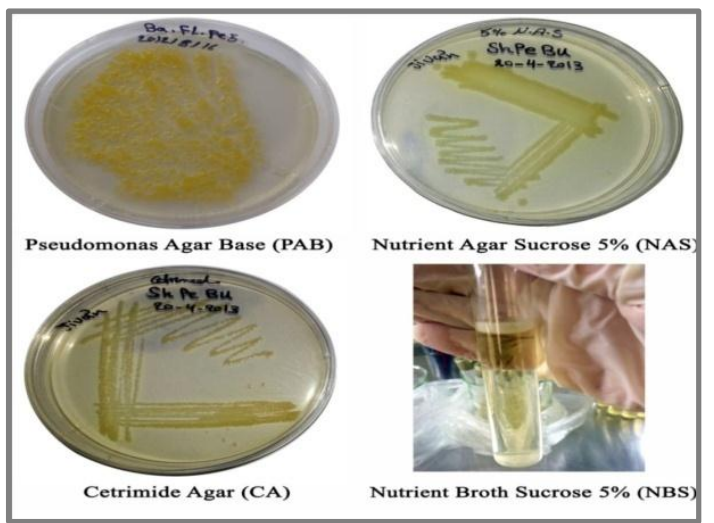

Figure 1: Growth of characteristic, mucoid and shiny colonies of Pseudomonas syringae pv. syringae , 2 days after inoculation on different media.

Table 3: Initial identification of Pseudomonas syringae isolates on 5\% Nutrient Agar Sucrose (NAS),

\begin{tabular}{|c|c|c|c|c|c|c|c|c|c|}
\hline \multirow[b]{2}{*}{ Host } & \multicolumn{3}{|c|}{ Initial Identification } & \multicolumn{3}{|c|}{$\%$ Isolation } & \multicolumn{3}{|c|}{$\%$ Contamination } \\
\hline & NAS & PAB & CA & NAS & PAB & CA & NAS & PAB & CA \\
\hline Apricot & 104 & 48 & 26 & \multirow{4}{*}{100} & 46.15 & 54.17 & \multirow{4}{*}{0} & 53.85 & 45.83 \\
\hline Peach & 104 & 57 & 18 & & 54.81 & 31.58 & & 45.19 & 68.42 \\
\hline Plum & 54 & 34 & 18 & & 62.96 & 52.94 & & 37.04 & 47.06 \\
\hline Total & 262 & 139 & 62 & & 53.05 & 44.60 & & 46.95 & 55.40 \\
\hline
\end{tabular}

\subsection{Identification of Bacterial Strains using traditional methods}

According to standard operating procedures, all 62 of tested isolates were gram negative, short rods, no spore-form, aerobic, oxidase negative and formation of distinctive mucoid that demonstrates as levan production on NAS (leaven positive). These morphological characteristics were also revealed by Mohammadi et al., (2001); Kaluzna et al., (2012).

\subsection{PCR identification of Bacterial Strains}

Genomic DNA Extraction: Suitable yields of genomic DNA were obtained from repeated experiments with an average yield of $50 \mu \mathrm{g}$ DNA per $\mu \mathrm{l}$ with purity about 1.46 to 2.56 determined by Nanodrop instrument and electronically by computer with adsorption reading at 260/280 nanometer.

Amplification by the Specific Primer: However, P. syringae has a broad host range, isolated from different plant hosts may comprise genetically distinct groups. So, the pathovars of these phytopathogenics that are associated with stone fruits produce several effective of such phytotoxin compounds as coronatine, phaseolotoxin, syringomycin, and tabtoxin which can be used for pathovar differentiation (Hwang et al., 2005). Thus, detection by PCR using specific primers could offer a reliable method for the confirmation of pathovars identity (Young, 2010; Gasic et al., 2012; Ivanovic et al., 2012). For differentiating the pathovars of 
Pseudomonas syringae, the PCR technique is rapid, simple reproductive to identify and classify phytopathogenic $P$. syringae at pathovar level and it may be a useful diagnostic tool for these important plant pathogens (Abu-Ashraf et al., 2000). In the present study, specific primer of Syringomycin (syrB) gene was used for identification of $62 P$. syringae isolates from conventional methods. The syrB gene was encoded synthesize syringomycin because these toxins are considered the main virulence factor of Pss (Young, 1991; Pour and Taghavi, 2011; Abbasi et al., 2013). Out of 62 isolates 13 (21\%) were amplified with specific primer of Syringomycin (syrB) gene (752 bp) whilst, the rest isolates are not amplified with it as shown in (Table 4 and Figure 2). Non amplified isolates were clarified, that they did not possess the syringomycine synthesize genes (Louws et al., 1999; Lopez et al., 2003). Other studies reported similar results of this strain from infected stone fruits (Sorensen et al., 1998; Scortichini et al., 2003; Gilbert et al., 2009; Kaluzna et al., 2010; Pour and Taghavi, 2011). In this direction, the specific pathovar identification of phytopathogenic Pseudomonads is more complicated than species detection. However, identification should always be confirmed by symptoms, host range and pathogenicity test that indicate potential target pathogens.

Table 4: PCR results of 62 isolates by specific primer of Syringomycin (syrB) gene.

\begin{tabular}{|c|c|c|c|c|c|}
\hline Bacterial Strain & syrB & Bacterial Strain & syrB & Bacterial Strain & syrB \\
\hline ShPeFl1 & + & AkP1Tw2 & - & FeApTr1 & - \\
\hline $\mathrm{ShPeFl2}$ & + & AkPlTw4 & - & FeApTr2 & - \\
\hline ShPlFl2 & + & ShPeTr1 & - & AkPeTr5 & - \\
\hline ShPlFl3 & + & ShPeTr5 & - & AkApTr1 & - \\
\hline GvPeFl3 & + & ShApTr3 & - & AkApTr3 & - \\
\hline GvPeFl4 & - & ShApTr4 & - & AkApTr4 & - \\
\hline GvApFl2 & + & ShApTr5 & - & AkPlTr1 & - \\
\hline GvApFl4 & - & GvPeTr1 & - & AkPlTr2 & - \\
\hline GvPlFl1 & - & GvPeTr2 & - & AkPlTr4 & - \\
\hline GvPlFl3 & - & GvPeTr3 & - & DlPeBu4 & - \\
\hline BaPeFl5 & + & GvApTr1 & - & ShApTw5 & - \\
\hline ShPeBu4 & + & GvApTr2 & - & GvPeTw2 & - \\
\hline ShPeBu5 & + & GvApTr4 & - & GvApTw2 & - \\
\hline ShApBu5 & + & GvPlTr1 & - & GvPlTw4 & - \\
\hline ShPlBu2 & - & GvPlTr2 & + & DlApTw5 & - \\
\hline GvApBu4 & - & GvPITr3 & - & AkApTw1 & - \\
\hline GvPlBu1 & - & GvPlTr4 & - & AkApTw2 & - \\
\hline GvPlBu2 & + & BaApTr3 & - & AkPlTw1 & - \\
\hline BaPeBu5 & + & BaApTr4 & - & DlApTr5 & - \\
\hline $\mathrm{BaApBu} 4$ & - & DlPeTr2 & - & FePeTr3 & - \\
\hline BaApBu5 & - & DlPeBu3 & - & & \\
\hline
\end{tabular}

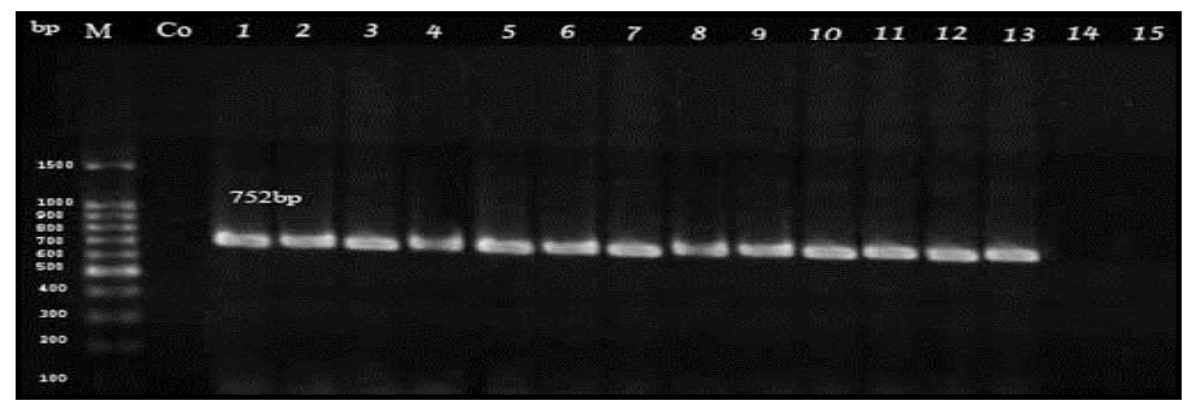

Figure 2: Agarose gel Electrophoresis of PCR with primers B1 and B2 corresponding to gene syrB, Co: Negative control, 1-13: Pseudomonas syringae pv. syringae strains 752bp, 14\&15 strains of P. syringae, M: 100-1500bp DNA molecular marker.

\subsection{Comparative PCR Results with Biochemical Tests}

Actually, the polymerase chain reaction (PCR) technique was firstly used to confirm the identification of the causal agent of bacterial canker which resulted in thirteen pure strains of Pseudomonas syringae pv. syringae (Pss) to thrift the cost and time before application of the Analytical Profile Index (API 20NE) to recognize the biochemical characteristic features of 13 Pss, since the initial detection of plant pathogenic bacteria relied mainly on biochemical and physiological methods (Schaad et al., 2001), and according to Jones et al., (1993), the test strips of API 20NE utilize to determine the bacterial enzymatic activity on various substrates of strip and identify the genus level only of the most bacteria.

The results revealed that all 13 bacterial strains of Pss have the same biochemical characters (Figure 2 C). Five of eight conventional tests of API 20NE were negative in reduction of nitrates (NO3), indole production 
TRyptoPhane (TRP), p-galactosidase Para-NitroPhenyl-ßD-Galactopyranosidase (PNPG), Arginine DiHydrolase $(\mathrm{ADH})$ and GLUcose fermentation (GLU), whereas these strains were capable for hydrolysis $\beta$-glucosidase ESCulin (ESC), hydrolysis GELatin (GEL) and UREa (UREase) (Table 5). These results were also reported by Kazempour et al. (2007) and Bultreys and Kaluzna (2010) and considered as diagnostic biochemical characters for Pss.

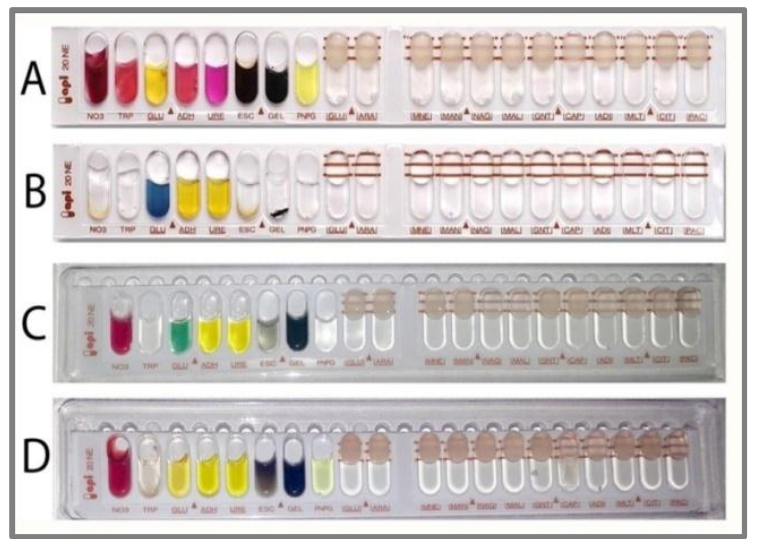

Figure 2: Biochemical reaction of API 20NE (A) Positive test, (B) Negative test, (C) Pseudomonas syringae pv. syringae and (D) Pseudomonas syringae.

Assimilation tests of N-Acetyl-Glucosamine (NAG), MALtose (MAL), ADIpic acid (ADI) and PhenylACetic acid (PAC) were negative, though the bacterial strains were able to utilize glucose (GLU), ARAbinose (ARA), ManNosE (MNE), MANnitol (MAN) and trisodium CITrate (CIT). Potassium GlucoNate (GNT), CAPric acid (CAP), MaLaTe (MLT) were also positive. Similar results were also reported by Kairu, (1997); Kazempour et al., (2007) and Bultreys and Kaluzna, (2010) to certify the identification of Pss.

Twelve unknown samples of $P$. syringae pathovar resulted from PCR were selected for testing their biochemical and physiological characters using strips of API 20NE. These samples were kept in a refrigerator to identify in the future when the primers of PCR become available. We found disparity in some reactions, such as GLUcose fermentation (GLU), Arginine DiHydrolase (ADH), UREase (URE), hydrolysis $\beta$-glucosidase ESCulin (ESC), GELatin hydrolysis (GEL) and p-galactosidase Para-NitroPhenyl-ßD-Galactopyranosidase (PNPG) (Figure 2 D). Therefore, we expect the occurrence of other pathovars of $P$. syringae, since for distinguishing pathovars within $P$. syringae that called GATTa tests are commonly used, including: Gelatine hydrolysis (G), Aesculin hydrolysis (A), Tyrosinase activity (T), Tartrate (Ta) utilization (Lelliot and Stead, 1987) and L-lactate utilization test (Lattore and Jones, 1979) in addition to more differences in the assimilation reactions.

Table 5: Biochemical characteristics of Pseudomonas syringae pv. syringae strains as assayed on different substrates by API 20NE tests.

\begin{tabular}{|l|l|c|}
\hline \multicolumn{1}{|c|}{ Substrate } & \multicolumn{1}{|c|}{ Reactions / Enzymes } & \multicolumn{1}{|c|}{ Pss } \\
\hline \multirow{2}{*}{ Potassium Nitrate } & Reduction of Nitrates to Nitrites & - \\
\cline { 2 - 3 } & Reduction of Nitrates to Nitrogen & - \\
\hline L-tryptophane & Indole production (tryptophane) & - \\
\hline D-Glucose & Fermentation (Glucose) & - \\
\hline L-Arginine & Arginine Dihydrolase & - \\
\hline Urea & UREase & + \\
\hline Esculin Ferric Citrate & Hydrolysis (B-Glucosidase) (Esculin) & + \\
\hline Gelatin (Bovine Origin) & Hydrolysis (Protease) (Gelatin) & + \\
\hline 4-Nitrophenyl-Pd-Galactopyranoside & P-Galactosidase(Para-NitroPhenyl-BD-Galactopyranosidase) & - \\
\hline D-Glucose & Assimilation (Glucose) & + \\
\hline L-Arabinose & Assimilation (Arabinose) & + \\
\hline D-Mannose & Assimilation (Mannose) & + \\
\hline D-Mannitol & Assimilation (Mannitol) & + \\
\hline N-Acetyl-Glucosamine & Assimilation (N-Acetyl-Glucosamine) & + \\
\hline D-Maltose & Assimilation (Maltose) & - \\
\hline Potassium Gluconate & Assimilation (Potassium Gluconate) & + \\
\hline Capric Acid & Assimilation (Capric Acid) & + \\
\hline Adipic Acid & Assimilation (Adipic Acid) & + \\
\hline Malic Acid & Assimilation (MaLaTe) & + \\
\hline Trisodium Citrate & Assimilation (Trisodium Citrate) & + \\
\hline Phenylacetic Acid & Assimilation (Phenylacetic Acid) & + \\
\hline & & + \\
\hline
\end{tabular}


*Provided by API 20NE diagnostic kit, (-) negative reaction, (+) positive reaction.

The investigated isolates shown in (Table 6) divided into three clearly distinct groups (1) positive reactions of gelatin (GEL) and esculin (ESC) hydrolysis of the isolates BaApBu4, GvApTw2, ShApTr4 and FeApTr1 may be attribute to $P$. syringae pv. morsprunorum race2 admitting to identification methods of (Kaluzna et al., 2012). (2) The isolate GvPlFl1 that didn't hydrolyze gelatin and esculin may referred to $P$. syringae pv. morsprunorum race1 or pv. persicae. The same result was also confirmed by Lattore and Jones (1979) and Burkowicz and Rudolph (1994). (3) Isolates of GvApFl4, ShApBu5, ShPlBu2, GvApBu4, DIPeBu3, ShPeTr1 and GvApTr4 with a positive reaction of the esculin and negative in gelatin tests in their metabolic processes. Thus, according to numerical taxonomy of biochemical tests and Rep- PCR conducted by Menard et al. (2003) signifying that they are phenon $5=P$. s. pv. papulans or $P$. syringae or phenon $10=P$. syringae pv. morsprunorum.

Table 6: Biochemical reactions of twelve unknown bacterial isolates.

\begin{tabular}{|c|c|c|c|c|c|c|c|c|c|c|c|c|}
\hline \multirow[b]{2}{*}{$\stackrel{\overrightarrow{0}}{\mathscr{0}}$} & \multicolumn{12}{|c|}{ Pseudomonas syringae isolates } \\
\hline & $\sum_{0}^{\frac{\pi}{2}}$ & $\frac{\bar{c}}{\frac{1}{2}}$ & ऊ & $\frac{\mathfrak{B}}{\text { 音 }}$ & 竞 & 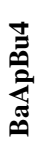 & 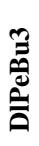 & $\frac{N}{3}$ & 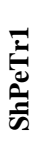 & 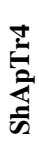 & 离 & 豙 \\
\hline \multirow{2}{*}{ NO3 } & - & - & - & - & - & - & - & - & - & - & - & - \\
\hline & - & - & - & - & - & - & - & - & - & - & - & - \\
\hline TRP & - & - & - & - & - & - & - & - & - & - & - & - \\
\hline GLU & + & + & + & + & + & + & + & + & - & + & + & + \\
\hline ADH & - & - & - & - & - & - & - & - & + & - & - & - \\
\hline URE & - & - & - & - & - & - & - & - & - & - & - & - \\
\hline ESC & + & - & + & + & + & + & + & + & + & + & + & + \\
\hline GEL & - & - & - & - & - & + & - & + & - & + & - & + \\
\hline PNPG & + & + & + & + & - & + & + & + & - & + & + & + \\
\hline GLU & + & + & + & + & + & + & + & + & + & + & + & + \\
\hline ARA & + & + & + & + & + & + & + & + & + & + & + & + \\
\hline MNE & + & + & + & + & + & + & + & + & + & + & + & + \\
\hline MAN & + & + & + & - & + & + & + & + & + & + & + & + \\
\hline NAG & + & + & + & + & + & + & + & + & + & + & + & + \\
\hline MAL & + & + & + & + & + & - & + & + & - & + & - & + \\
\hline GNT & + & + & + & + & + & + & + & + & + & + & + & + \\
\hline CAP & + & - & + & + & + & + & + & + & + & + & + & - \\
\hline ADI & - & - & - & - & - & - & - & - & - & - & + & - \\
\hline MLT & + & + & + & + & + & + & + & + & + & + & + & + \\
\hline CIT & + & - & + & + & + & + & + & + & + & + & + & + \\
\hline PAC & - & - & - & - & - & - & - & - & - & - & - & - \\
\hline
\end{tabular}

\section{Conclusion}

In this work we conclude that PCR identification of $P$. syringae pv. syringae (Pss) consider the first record of this suspected and serious phytopathogenic bacteria in Iraq. Detection using PCR is reliable method for the confirmation of pathovars. Syringomycine (syrB) gene the main virulence factors of Pss, since induces necrosis in host tissues and typical chlorosis of leaves as a result of chloroplast disruption. Therefore, thirteen isolates could synthesize this toxin that assists the identification and characterization of putative Pss strains.

\section{References}

[1]. Cameron, H.R. (1962) Disease of deciduous fruit trees incited by Pseudomonas syringae Van Hall. Oregen Agric. Exp.st. Tech. Bull, pp.64-66.

[2]. Ogawa, J.M. and H. English (1991) Diseases of temperate zone tree fruit and nut crops. Publication: 3345.

[3]. Young, J.M. (1991) Pathogenicity and identification of the lilac pathogen, Pseudomonas syringae pv. syringae van Hall 1902. Annual of Applied Biology, 118:283-298.

[4]. Mohammadi, M.; A. Ghasemi and H. Rahimian (2001) Phenotypic characterization of Iranian strains of Pseudomonas syringae pv. syringae Van Hall, the causal agent of bacterial canker disease of stone fruit trees. Journal of Agricultural Science and Technology, 3(1):51-65.

[5]. Gardan, L.; H. Shafik and S. Belouin (1999) DNA relatedness among the pathovars of Pseudomonas syringae and description of Pseudomonas tremae sp. Nov. and Pseudomonas cannabina sp. Nov. (ex Sutic and Dowson 1959) International Journal of Systematic Bacteriology, 49:469-478.

[6]. Roberts, T.S. and T.J. Smith (2002) Crop protection guide for tree fruits in Washington. Washington state university extension bulletin EB0419. 
First Record of Pseudomonas syringae pv. syringae in Iraq using Conventional and Specific PCR

[7]. Kennelly, M. M. 1.; F. M. Cazorla; A. de Vincent; C. Ramos and G. W. Sundin (2007) Pseudomonas syringae diseases of fruit trees, progress toward understanding and control. Plant Disease, 91:4-17.

[8]. Young, J.M. (2010) Mini review taxonomy of Pseudomonas syringae . Journal of Plant Pathology, 92(1):5-14.

[9]. Young, J.M. and C.M. Triggs (1994) Evaluation of determinative tests for pathovars of Pseudomonas syringae van Hall 1902. Journal of Applied Bacteriology 77:195-207.

[10]. Palleroni, N.J. (2005) Genus I. Pseudomonas In: Brenner D.J., Krieg N.R., Staley J.T., Garrity G.M., (Eds) Bergey's Manual of Systematic Bacteriology. $2^{\text {nd }}$ ed. The Proteobacteria, Part B Gamma proteobacteria, Springer, New York, NY, USA, 2:323-379.

[11]. Najafi, P.H.G. and S. M. Taghavi (2014) Discrimination of Pseudomonas syringae pv. syringae isolates from different hosts in Iran using pathogenicity tests and RAPD. International Journal of Agri. Science, 4(1):16-27.

[12]. Palacio-Bielsa A., C.M.A. and L.M.M. (2009) PCR detection and identification of plant-pathogenic bacteria: updated review of protocols (1989-2007). Journal of Plant Pathology, 91: 249-297.

[13]. Fahy, P.C. and G.J. Persley (1983) Plant bacterial disease, a diagnostic guide. Academic press, London, handbook. Pag. 377.

[14]. York, M. K.; M. M. Taylor; J. Hardy and M. Henry (2004) Biochemical tests for the identification of aerobic bacteria, Clinical microbiology procedures handbook, ( $2^{\text {nd }}$ Ed.). ASM Press, Washington, DC, 3.17-39.1.

[15]. Sorensen, K.N., K.H. Kim and J.Y. Takemoto (1998) PCR detection of cyclic lipodepsinoapeptide-producing Pseudomonas syringae pv. syringae and similarity of strains. Applied and Environmental Microbiology, 64:226-230.

[16]. Vogelstein, B. and D. Gillespie (1979) Preparative and analytical purification of DNA from agarose. Proc. Natl. Acad. Sci. USA, pp. 76.

[17]. Tyc, O. (2011) Exploration of Pseudomonas fluorescents Pf0-1 secondary metabolite production and competitive interaction. Diploma Thesis, University of Hohenheim, pp. 22.

[18]. Maniatis, T.; E.F. Fritsch and J. Sambrook (1982) Molecular cloning A laboratory manual cold spring harbor laboratory, New York, U.S.A.

[19]. Gaafar, T.M.; A.M. ELBeshlawy; M. Aziz and H.N. Abdelrazik (2006) Rapid screening of $\beta$-Globin gene mutations by Real-Time PCR in Egyptian thalassemic children. African Journal of Health Sciences, 13:70.

[20]. Pour, G.N. and S.M. Taghavi (2011) Comparison of P. syringae pv. syringae from different hosts based on pathogenicity and box PCR in Iran. J. Agr. Sci. Tech., 13:431-442.

[21]. Takemoto, J.Y. (1992) Bacterial phytotoxin syringomycine and its interaction with host membranes. In: Verma DPS, editor. Molecular Signals in Plant-microbe communication. Boca Raton, Fla, CRC press: 247-260.

[22]. Karimi-Kurdistani, G. and B. Harighi (2008) Phenotypic and molecular properties of Pseudomonas syringae pv. syringae the causal agent of bacterial canker of stone fruit trees in Kurdistan province. Journal of Plant Pathology, 90:81-86.

[23]. Moore, E.R.B.; B.J. Tindall; V.A.P. Martins Dos Santos; D.H. Pieper; J. Ramos and N.J. Palleroni (2006) Prokaryotes nonmedical Pseudomonas, chapter three: 646-703.

[24]. Kaluzna, M.; J.D. Janse and J.M. Young (2012) Detection and identification methods and new tests as used and developed in the framework of cost 873 for bacteria pathogenic to stone fruits and nuts Pseudomonas syringae pathovars. Journal of Plant Pathology, 94:117-126.

[25]. Hwang, M.S.H.; R.L. Morgan; S.F. Sarkar; P.W. Wang and D.S. Guttman (2005) Phylogenetic Characterization of Virulence and Resistance Phenotypes of Pseudomonas syringae. Applied and Environmental Microbiology, 71(9):5182-5191.

[26]. Gasic, K.; P. Anđelka; I. Milan; K. Nemanja and O. Aleksa (2012) Differentiation of Pseudomonas syringae Pathovars Originating from Stone Fruits. Pestic. Phytomed, 27(3):219-229.

[27]. Ivanovic, Z.; S. Stankovic; S. Zivkovic; V. Gavrilovic; M. Kojic and D. Fira (2012) Molecular characterization of Pseudomonas syringae isolates from fruit trees and raspberry in Serbia. Eur J Plant Pathol. 134:191-203.

[28]. Abu-Ashraf, K.; N. Furuya; M. Matsumoto and N. Matsuyama (2000) Differentiation of phytopathogenic Pseudomonas and Xanthomonas pathovars and strains by PCR analysis for DNA topoisomerase genes. Journal of the Faculty of Agriculture, Kyushu University, 45(1):1-6.

[29]. Abbasi, V.; H. Rahimian and M.A. Tajick-Ghanbari (2013) Genetic variability of Iranian strains of Pseudomonas syringae pv. syringae causing bacterial canker disease of stone fruits. European journal of plant pathology, 135:225-235.

[30]. Louws, F.J.; J.L.W. Rademaker and F.J. de Bruijn (1999) The three Ds of PCR-based genomic analysis of phytobacteria: Diversity, detection, and disease diagnosis. Annual Review of Phytopathology, 37:81-125.

[31]. Lopez, M.M.; E. Bertolini; A. Olmos; P. Caruso; M.T. Gorris; P. Llop; R. Penyalver and M. Cambra (2003) Innovative tools for detection of plant pathogenic viruses and bacteria. International Microbiology, 6:233-234.

[32]. Scortichini, M.; U. Marchesi; M.T. Dettori and M.P. Rossi (2003) Genetic diversity, presence of the syrB gene, host preference and virulence of Pseudomonas syringae pv. syringae strains from woody and herbaceous host plants. Plant Pathology, 82:277-286.

[33]. Gilbert, V.; F. Legros; H. Maraite and A. Bultreys (2009) Genetic analyses of Pseudomonas syringae isolates from Belgian fruit orchards reveal genetic variability and isolate-host relationships within the pathovar syringae, and help identify both races of the pathovar morsprunorum. European Journal of Plant Pathology, 124:199-218.

[34]. Kaluzna, M.; J. Pulawska and P. Sobiczewski (2010) The use of PCR melting profile for typing of Pseudomonas syringae isolates from stone fruit trees. European journal of plant pathology, 126:437-443.

[35]. Schaad, N.W.; J.B. Jones and W. Chun (2001) Laboratory Guide for Identification of Plant Pathogenic Bacteria $3^{\text {rd }}$ ed. American Phytopathological Society Press, St. Paul, MN, USA.

[36]. Jones, J. B.; A. R. Chase and G. K. Harris (1993) Evaluation of the Biology GN Micro Plate system for identification of some plantpathogenic bacteria. Plant disease, 77:553-558.

[37]. Kazempour, M. N.; F. Jamie and S. Ali (2007) Bacterial canker cause by Pseudomonas syringae pv. syringae on stone fruits in Guilan province of Iran. International Journal of Biology and Biotechnology, 4(4):373-378

[38]. Bultreys, A. and M. Kaluzna (2010) Bacterial cankers caused by Pseudomonas syringae on stone fruit species with special emphasis on the pathovars syringae and morsprunorum race 1 and race 2. Journal of Plant Pathology, 92(1):21-33.

[39]. Kairu, G. M. (1997) Biochemical and pathogenic differences between Kenyan and Brazilian isolates of Pseudomonas syringae pv. garcae. Plant Pathology, 46:239-246.

[40]. Lelliott, R.A. and D.E. Stead (1987) Methods for the diagnosis of bacterial diseases of plants. In: Preece T.F. (Ed.) Methods in Plant Pathology Blackwell Scientific Press, oxford, London, UK., 2:216.

[41]. Lattore, B. A. and A. L Jones (1979) Pseudomonas morsprunorum, the cause of bacterial canker of sour cherry in Michigan and its epiphytic association with P. syringae . Phytopathology, 69:335-339.

[42]. Burkowicz, A. and K. Rudolph (1994) Evaluation of pathogenicity and of cultural and biochemical tests for identification of Pseudomonas syringae pathovars syringae, morsprunorum, and persicae from fruit trees. Journal of Phytopathology, 141:59-76.

[43]. Menard, M.; L. Sutra; J. Luisetti; J. P. Prunier and L. Gardan (2003) Pseudomonas syringae pv. avii (pv. nov.), the causal agent of bacterial canker of wild cherries (Prunus avium) in France. European Journal of Plant Pathology, 109:565-576. 